\title{
COMMUNICATION AND ART
}

\author{
Helena Pires, Silvana Mota-Ribeiro \& Anne Beyaert-Geslin
}

The $31^{\text {st }}$ issue of the journal, Comunicação e Sociedade, is dedicated to the theme "Communication and Art". The present issue, gathers a collection of texts covering a wide array of problematics, approaches and methodologies, that explore a diverse range of modalities and artistic languages, including dance, theatre, the cinema and the visual arts. The cases presented and the different art forms under analysis and reflection, express a cultural polyphony, consisting of a combination of the Portuguese-speaking world and European cultural heritage in general, but also the idiosyncratic characteristics of culture and the arts in Portugal (in interaction with the sphere of inter-culturality). References are made to a significant range of artistic practices, and to the critical thinking fostered by the artistic sector, in articulation with the field of communications.

Given the combination of such a plurality of different perspectives in the context of this issue, it is worthwhile pondering the various possible conclusions that may be drawn from these different texts, authors, and realities and objects. Any compilation of texts by several authors, even if anchored on a theme somehow shared, is always, we might say, a "provocation", a meeting space that destabilizes the limits of pre-given signification that each text preserves, in its illusory autonomy in intra-discursive terms. Inevitably, this publication is first and foremost an inventor of new meanings, a producer of connections, but also of debatable classifications, with a view to proposing new interpretations. Ultimately this is an exercise in hermeneutics - that proceeds from explanation of the work and the author to an understanding of that which has caught, or continues to catch, the interest of the editors, who are involved in a wide range of different concerns, and theoretical and methodological problems, shared by the academic and artistic communities. This issue, thus, addresses an approximation between communication, in its possibilities of interrogation on the public, mediation, discourses produced in the field of culture and the arts, on the one hand, and art itself, in its intermodal and interdisciplinary multiple dimensions, in the ways in which it increasingly calls upon the skills and potential of communication, both in artistic creation and in artistic production, on the other. Ultimately, this will involve discussion, at least at an implicit level, of the porosity of the boundaries between art and science. This debate is even more relevant today, given that we have witnessed a profound ontological and epistemological crisis, that transcends a wide array of social and cultural practices and representations. This issue aims to explore the field of communication, in terms of the way that it challenges art. The texts published herein, which we will now briefly summarise, are stimulating starting points.

Firstly we would like to clarify the interpretational guidelines that headed this particular order of the texts presented in this issue, as well as the proposed reading that to a certain extent enables them to somehow establish new meanings between each other. 
This isn't a question of merely listing subjects or sub-themes, before trying to suggest more or less explicit levels of affinity between several texts, that enable us to see them in a specific light, when perceived in terms of their articulation with the publication as a whole.

The issue commences with four texts, each addressing the performing arts from a unique perspective. Mateus Yuri Passos, in his text, "The world in a bottle and the archeology of staging: audiovisual recording as registers of opera productions", explores "the use of audiovisual recordings as documents for analysis of contemporary opera productions, grouped by German critics under the term director's theatre [Regietheater]". On the basis of detailed analysis of several excerpts from Richard Wagner's The Ring of the Nibelung, the author highlights the differences in terms of the autonomy of the various dimensions of the complete work (verbal, musical and visual) when compared to staging and recording the opera, thus contributing to an understanding of the specificities of this artistic medium, in particular its implications in terms of directing. The following text is by Né Barros, entitled "Dance and mediality: for an ontological and ethical discussion of the performative body". The article proposes the concept of mediality, to designate both the "political and ethical stage" and the "ontological space" fostered by dance. The author argues that it makes sense to use this concept due to expansion of frontiers within the history of dance, as a result of a rupture that has transformed the body and performativity into a particularly tense and discursive relationship.

After discussion and analysis of the specificities of the medium, and the limitations and possibilities of transmediality, in relation to operatic productions, as well as an autopoietic reflection concerning the transformations that have taken place in the world of dance, the two following texts are case studies that propose a critical interpretation fostered by the world of theatre, in its assumedly political and interventive dimension. "Monsters, machines and popcorn: theatre of the oppressed and street protest", by Inês Barbosa and Fernando Ilídio Ferreira, encourages us to reflect on different ways of thinking about the European crisis, or rather the crisis in Portugal, on the basis of performance-based provocations and street protests of "theatre of the oppressed." The article discusses the Theatre of the Oppressed as "a collective action and critical education tool, within the context of contemporary social mobilizations", in particular with a view to stimulating deeper reflection (in view of its role of promoting intervention and participation) about the present-day capitalist system. This is followed by the article, "House on Fire: a political and collaborative art case", by Teresa Mora. The main idea defended by the article is the manner that artistic practices currently promote "the transition towards a collaborative model between artistic culture, and scientific-social and philosophical culture". For this purpose, the author uses analysis and discussion of materials (activity plans and programmes) related to the activity pursued between 2012 and 2015 by the European network of theatres and festivals, entitled House on Fire.

The second part of this issue presents another set of four texts, that address the worlds of cinema, photography, painting and the visual arts. Using different approaches, problems and analytic methodologies, the articles explore multiple cultural implications 
in cinematographic and visual artistic production, concerning different ways of perceiving and seeing. Caterina Cucinotta, in her article "Pathways of analysis on costume in Portuguese ethnofiction films", proposes to operationalize the concept of ethno-fiction through analysis of three trilogies of Portuguese cinema. The article aims to analyse the specificities of clothing used in Portuguese cinema, in articulation with the theory of fashion and a specific ethnographic and cultural narrative. Eliza Bachega Casadei and Mariana Duccini, in their article, "Violent objects: the forms of pathos in Yael Martinez, Glenna Gordon e Eugênio Grosso's compositions", analyse the iconology of consumption objects, questioning the manner whereby the three photographers achieve certain visual composition strategies. Violence is the common theme that crosses the works under analysis, which evoke various different forms of pathos. This second set of texts also includes, "On the 'Garden of Delights' as a model of analysis of the intercultural communication processes", by Lurdes Macedo. Based on Bosch's "Garden of Delights", and analysing it from the perspective of intercultural communication, the author aims to propose a reading capable of contributing to the defragmentation of collective memory, anchored in global trajectories, namely of intercontinental navigation, in which Portuguese and Spanish navigators played a special role. This second group of texts is completed by a text by Sílvia Pinto and Moisés de Lemos Martins - "Binding logics in art". Approaching the metaphysics of the image, from a historical perspective, this article suggests an approximation between the world of art and religion. In the current context, the authors seek to "show the importance of art and its mythical-religious ascendance in what concerns media image redefinition".

Finally, this issue includes a third set of three texts which address the link between art and technology. The first is an article entitled "Media, art and technology: a contemporary reflection", by Fernando Augusto Silva Lopes. What role does technology play in mass media dissemination and commodification of culture and the arts in the contemporary era? The author aims to discuss this question, together with its implications for cultural and social changes in the modern world. The article also aims to address the manner in which artistic practices highlight and question the influence of the media, and the market. This is followed by a text on the current situation of the Brazilian music industry, by Daniel Ferreira Wainer entitled "Between music and technology: existence and functioning conditions of the Brazilian phonographic industry in the $21^{\text {st }}$ century". Based on empirical research, the author explores the effects, ruptures and continuities associated to digitization, including analysis of issues such as piracy and copyright. The article, "Communication of art via open research: on cultural policies, heritage and reception of innovation in art", by Pedro Andrade discusses key concepts for artistic communication and public communication of art, in which new technologies play a specific role, especially in relation to issues such as artistic literacy. The article offers practical recommendations for research in these areas (via open research), proposing an agenda and also providing a glossary on the subject area.

The set of articles are completed by a text by Ludovic Chatenet and Anne BeyaertGeslin, which discusses the thematic articulation (communication and art) underlying 
this issue. Entitled "From communication to art: McDonald's and flat design", the article offers a semiotic analysis of McDonald's 2015 advertising campaign ads, created by the TBWA agency in Paris. Based on this analysis, the authors suggest a new rhetoric for the image, according to which "todays' societies, defined as hypermodern, no longer trade objects but forms of life, subscription values to users communities". To understand this paradigm shift it is necessary to question the processes of aestheticisation and "artistisation" fostered by contemporary culture.

The second section of this thematic issue includes a critical review by Anabela Veloso Rodrigues of a recent publication by Luís Ferreira Alves, that analyses the role of photography in Eduardo Souto de Moura's architectural work.

On the basis of this itinerary, only slightly unveiled in this introduction, we invite you to read the texts, as we are convinced that further reflecting and researching art-communication is currently one of many promising possibilities for (de)constructing knowledge ...

Traduzido por Martin Dale (Sombra Chinesa)

\section{BIOGRAPHICAL NOTES}

Helena Pires is an Assistant Professor in the Department of Communication Sciences, at the Institute of Social Sciences of the University of Minho (UM), and a researcher at the UM's Communication and Society Research Centre (CECS).

She has a PhD in Semiotics of Communication from the University of Minho and is currently pursuing research in the areas of Semiotics and Visual Culture, Urban Culture and Advertising. She has developed research into the topic of the Landscape and its representation in contemporary art. Most recently, within the framework of CECS, she has co-coordinated the project, Passeio, urban arts and culture platform. She teaches subjects such as Semiotics, Advertising and Art, Media and Communication, among others. She is currently a member of the Management Board of the Master's Degree in Communication, Art and Culture.

E-mail: hpires@ics.uminho.pt

Department of Communication Sciences, ICS, University of Minho, Campus de Gualtar, 4710-057 Braga, Portugal

Silvana Mota Ribeiro is Assistant Professor of the Institute of Social Sciences, University of Minho. She teaches in the areas of visual culture and semiotics, art, fashion and strategic communication. She pursues research in the area of gender discourses, image analysis, social semiotics and multimodality. She is currently a member of the Management Board of the Master's Degree in Communication, Art and Culture.

E-mail: silvanar@ics.uminho.pt

Department of Communication Sciences, ICS, University of Minho, Campus de Gualtar, 4710-057 Braga, Portugal 
Anne Beyaert-Geslin is professor of semiotics and communication at BordeauxMontaigne University and director of the MICA (Mediations, Information, Communication, Arts) research team. She has edited sixteen collective books and review issues (in 2017 with Maria Giulia Dondero and Audrey Moutat, Les plis de l'image. Reflexivité et énonciation dans l'image, Lambert Lucas) and 4 books: L'image préoccupée, Hermès-Lavoisier, 2009; Sémiotique du design, Presses Universitaires de France, 2012 (italian translation in 2017: Semiotica del design, Rimini, ETS Edition); Sémiotique des objets, la matière du temps, Presses Universitaires de Liège, collection Sigilla, 2015. Méthodes du portrait is to be published by De Boeck in 2017.

She has also written about 120 articles about semiotics of image, media and design in French, Italian, Spanish, English, Chinese, Portuguese and Persian.

E-mail: anne.geslin-beyaert@u-bordeaux-montaigne.fr

Bordeaux-Montaigne University. Domaine Universitaire, 19 esplanade des Antilles, 33607 Pessac, France 